\title{
The Effectiveness of Mindfulness-Based Thriving Programs on High School Students' Perceived Stress, Mindfulness, Thriving and Self-Efficacy Levels
}

\author{
Neslihan Arıcı Özcan* \\ Received: September 17, 2020; received in revised form: November 20, 2020; \\ accepted: November 23, 2020
}

\begin{abstract}
:
Introduction: Adolescence is a period of rapid change marked by increased stress levels. Individuals with high self-efficacy better alleviate the effects of the stress of this period by exerting conscious control over their own thoughts, behaviours and feelings - a trait strongly associated with mindfulness. In this regard, the concept of mindfulness-based selfefficacy has been a much-researched area in recent students. Mindfulness practices ensure individuals with vitality and energy since they learn to become more open and engaged. In this respect, mindfulness is associated with thriving. This experimental research investigates the effects of the Mindfulness-Based Thriving Program (MTP) on high school students' perceived stress, mindfulness, thriving and self-efficacy levels.

Methods: The study was conducted with 17 randomly assigned, female 11 th grade students $(\bar{X}=16.62$ for experimental group, $\bar{X}=16.77$ for control group), who acquired educational support in Uskudar Municipality Youth Academy in the 2019-2020 academic year. The inclusion criteria included scoring highly on the Perceived Stress Scale (PSS) and scoring lowly on the Mindfulness Attention Awareness Scale (MAAS), Thriving Scale (TS) and Self-Efficacy Scale (GSES) in a pre-test assessment. The experimental group $(n=8)$ received a six-session MTP intervention developed by the researcher, while the control group $(n=9)$ received no intervention. To determine the immediate and long-term effects of the MTP, all participants completed post-tests (PSS, MAAS, TS, GSES) two months after the program.
\end{abstract}

Results: The 6-week MTP applied to adolescents was significantly effective in decreasing perceived stress and increasing mindfulness, thriving and self-efficacy levels.

Discussion: All findings were supported by the relevant literature and recommendations on their possible application have been given.

\footnotetext{
* Neslihan Arıcı Özcan, İstanbul Medeniyet University, Istanbul, Turkey; neslihan.ozcan@medeniyet.edu.tr
} 


\title{
Acta Educationis Generalis \\ Volume 12, 2022, Issue 1
}

\begin{abstract}
Limitations: Scores obtained from the scales, the narrow range of the sample (only 11th grade female students), the lack of a placebo group to support reliability and the lack of a comparable program for the current one all indicated the limitations of the study.

Conclusions: The 6-week MTP applied to adolescents showed the effectiveness in decreasing perceived stress and increasing mindfulness, thriving and self-efficacy levels. In this regard, thriving and mindfulness together have an important role in the development of self-efficacy and in decreasing perceived stress during adolescence. Thus, all these conclusions highlight the potential contribution of eclectic mindfulness practices for adolescence.
\end{abstract}

Key words: mindfulness, mindfulness-based thriving program, perceived stress, self-efficacy, thriving.

\section{Introduction}

Youth in today's world, especially middle adolescents, are faced with increasing challenges in several domains of development - not least in the academic, social, and cognitive realms. These features need to be successfully managed in order to ensure their adaptive functioning (Arnett, 2007; Byrne, Davenport, \& Mazanov, 2007; Neff \& McGehee, 2010). Therefore, adolescence is characterized by increased stress levels (Neff \& McGehee, 2010). In Turkey, high school students in particular experience higher levels of stress due to the intense pressure instilled in them by university entrance exams (Dogan \& Kuzgun, 2008; Hevedanlı \& Ekici, 2011; Melman, Little, \& Akin-Little, 2007). These stressors force adolescents to seek to distance themselves from their future goals and school environment (Hevedanlı \& Ekici, 2011; Şahin, Gunay, \& Bati, 2006). Accordingly, the protective factors needed to cope with these stressors gain importance during adolescence.

One of the preventive factors in the face of stressors is self-efficacy. Selfefficacy is concerned with people's beliefs in their own capabilities to manage stressful situations (Cicognani, 2011; Greason \& Cashwell, 2009). Individuals with high self-efficacy better alleviate the effects of stress by exerting conscious control over their own thoughts, behaviours and feelings, in a stance strongly associated with mindfulness. Most studies provide supportive evidence for the relationship between mindfulness and self-efficacy (Blecharz, Luszczynska, Scholz et al., 2014; Caldwell, Harrison, Adams, Quin, \& Greeson, 2010; Muris, Meesters, Pierik, \& de Kock, 2016). In this regard, the concept of mindfulnessbased self-efficacy has been the subject of recent investigations (Atalay, Bulgan, \& Taylan, 2017; Chang, Palesh, Caldwell et al., 2004; Cayoun, Francis, Kasselis, \& Skilbeck, 2012; Ozkan, Karatas, \& Ergin, 2018) and is defined as the person's ability to maintain awareness without judgment in various situations (Chang et al., 2004). More broadly, mindfulness encompasses the monitoring of 


\section{Acta Educationis Generalis \\ Volume 12, 2022, Issue 1}

inner experiences in the present moment via attention, being aware of the nature of this attention and admitting it without judgment (Kabat-Zin, 2015). This admittance contains the continuous observation of all body sensations, emotions, thoughts and their regulation (Bishop, Lau, Shapiro et al., 2004; Davidson, Kabat-Zinn, Schumacher et al., 2003; Nielsen \& Kaszniak, 2006; Creswell, Way, Eisenberger, \& Lieberman, 2007). Most studies show that mindfulness practices increase well-being, strengthen academic performance and decrease the stress levels (Hölzel, Lazar, Gard et al., 2011; Zenner, Herrnleben-Kurz, \& Walach, 2014), since all body sensations, feelings and thoughts are taken as "simply" body sensations, feelings and thoughts - rather than stable features. Mindfulness practices especially help young people to concentrate on tasks. Concentration via focused attention may reduce anxiety and improve academic performance (Beauchemin, Hutchins, \& Patterson, 2008; Franco, Mañas, Cangas, \& Gallego, 2010), as well as foster curiosity and openness (Coffman, 2007; Siegel, 2007). In other words, mindful practices ensure individuals vitality and energy (Allen \& Kiburz, 2012; Baer \& Lykins, 2011; Brown \& Ryan, 2003), since they learn to be open and engaged (Siegel, 2007). In this respect, mindfulness can be associated with thriving. Although many studies have indicated a relationship between mindfulness and thriving in various samples (workers, nurses) (Allen \& Kiburz, 2012; Baer \& Lykins, 2011; Brown \& Ryan, 2003; Siegel, 2007; Şahin, Arıcı Özcan, \& Arslan Babal, 2020), only a few studies (Tan \& Martin, 2015; Warren, 2016) have looked at the relationship between mindfulness and thriving among adolescents. To bridge this gap, the current study aimed to examine the relationship between mindfulness practices and thriving in a sample of adolescents.

Thriving is a concept of positive psychology and has many different definitions depending on the specific sample and context of the study (Brown, Arnold, Fletcher, \& Standage, 2017). Broadly, it can be defined as a psychological state that gives an individual the inner energy and confidence to learn certain skills or knowledge with greater enthusiasm (Nix, Ryan, Manly, \& Deci, 1999; Spreitzer, Sutcliffe, Dutton, Sonenshein, \& Grant, 2005). Most studies (Deci \& Ryan, 2008; Spreitzer et al., 2005; Wallace, Butts, Johnson, Stevens, \& Smith, 2016) indicate that those with thriving features navigate and regulate their internal sources and behaviours autonomously according to their basic psychological needs and contextual features. Thus, thriving allows individuals to assess their capabilities and improve themselves accordingly (Spreitzer et al., 2005), which might be beneficial while facing with difficulties and stressors. Specifically, thriving programs foster resource development among teens, giving them academic motivation and connection skills while decreasing their behaviour problems (Arnold, 2017; 2018; Arnold \& Gagnon, 2019; DuBois \& Keller, 2017; Lerner, Lerner, von Eye, Bowers, \& Lewin-Bizan, 2011). In this sense, several researchers have emphasized the relationship between thriving and self- 


\section{Acta Educationis Generalis \\ Volume 12, 2022, Issue 1}

efficacy - especially among adolescence (Deane, Harré, Moore, \& Courtney, 2017; Hirschi, 2009; Scales, Benson, \& Roehlkepartain, 2011).

All above-mentioned studies point to the importance of understanding human development from a strength-centred perspective. Focusing on personal resources instead of problems and inadequacies appears to be critical, while developing interventions to protect individuals against the risk factors (Bundick, Yeager, King, \& Damon, 2010). Given the challenges regarding youth developmental issues, researchers have recognized the need to improve adolescents' well-being through effective intervention programs. "Positive Youth Development (PYD)" is one such programs developed to strengthen the internal and external resources of adolescences, such as their self-efficacy and self-regulation which have a great impact on maintenance and enhancement of their mental health (Lerner, Phelps, Forman, \& Bowers, 2009; Lerner et al., 2011). In particular, Mindfulness-Based Stress Reduction Programs (MBSR) are effective in nurturing self-efficacy and self-regulation (Bishop et al., 2004; Caldwell et al., 2010), as well as reducing levels of stress and anxiety among adolescents (Chang et al., 2004; Blecharz et al., 2014; Malow \& Austin, 2016; Sibinga, Kerrigan, Stewart et al., 2011). Furthermore, these programs have a significant role in the improvement of emotion regulation skills (Tacón, McComb, Caldera, \& Randolph, 2003; Siegel, 2007), control perception (Astin, 1997), and awareness (Cohen-Katz, Wiley, Capuano, Baker, \& Shapiro, 2005). Consequently, the enhancement of several different skills may play a critical role for adolescents to thrive with their life.

Most mindfulness studies have tended to examine mindfulness descriptively according to several variables, such as self-compassion (Ozyeşil, 2011), stress (Ülev, 2014) and social anxiety (Tuncer, 2017). Furthermore, the number of experimental studies is quite limited, and these limited studies mostly concentrated on the examination of stress (Demir, 2015, 2017) and emotion regulation (Demir \& Gündoğan, 2018) among university students. A small number of studies, meanwhile, have focused on self-efficacy and mindfulness in high school students (Atalay et al., 2017; Ozkan et al., 2018). More specifically, no study has covered the concepts of perceived stress, mindfulness, self-efficacy and thriving among high-school students - especially those in the 11Th grade, who have the added pressure of university entrance exams. Therefore, the current study has aimed to examine the effects of MTP on high school students' perceived stress, mindfulness, and self-efficacy levels. The study tested the following hypotheses to reach these aims. 


\section{Acta Educationis Generalis \\ Volume 12, 2022, Issue 1}

\section{Hypotheses}

$\mathrm{H}_{1}$ : MTP will be significantly more effective in decreasing the perceived stress levels of high school students in the experimental group than the control group; and this effect will be sustained in measurements to be conducted in two months following the completion of the program.

$\mathrm{H}_{2}$ : MTP will be significantly more effective in increasing mindfulness levels of high school students in the experimental group than the control group; and this effect will be sustained in measurements to be conducted in two months, following the completion of the program.

$\mathrm{H}_{3}$ : MTP will be significantly more effective in increasing thriving levels of high school students in the experimental group than control group; and this effect will be sustained in measurements to be conducted in two months following the completion of the program.

$\mathrm{H}_{4}$ : MTP will be significantly more effective in increasing self-efficacy levels of high school students in the experimental group than the control group; and this effect will be sustained in measurements to be conducted in two months following the completion of the program.

\section{Method}

\subsection{Research design}

The study examined the effects of MTP on high school student's perceived stress, mindfulness, thriving and self-efficacy levels. As seen below, the first factor shows the independent functional groups (experimental and control), while the other factor shows the repeated measurements (pre-test, post-test, follow up test) in various conditions, according to the dependent variable (Buyukozturk, 2006).

Table 1

\begin{tabular}{|c|c|c|c|c|}
\hline Groups & Pre-test & Intervention & Post-test & Follow up -test \\
\hline \multirow{4}{*}{ Experiment } & $\overline{\mathrm{PSS}}$ & & $\overline{\mathrm{PSS}}$ & $\overline{\mathrm{PSS}}$ \\
\hline & MAAS & (MTP) & MAAS & MAAS \\
\hline & TS & & $\mathrm{TS}$ & TS \\
\hline & GSES & & GSES & GSES \\
\hline \multirow[t]{4}{*}{ Control } & PSS & & PSS & PSS \\
\hline & MAAS & No intervention & MAAS & MAAS \\
\hline & TS & & $\mathrm{TS}$ & TS \\
\hline & GSES & & GSES & GSES \\
\hline
\end{tabular}

PSS: Perceived Stress Scale, MAAS: Mindfulness Attention Awareness Scale, TS: Thriving Scale, GSES: General Self-Efficacy Scale 


\section{Acta Educationis Generalis \\ Volume 12, 2022, Issue 1}

\subsection{Participants}

Participants were selected from among high school students receiving learning support at the Uskudar Municipality Youth Academy for the Fall semester of the 2019-2020 Academic Year. After consent was taken from the students and their families, 173 11th grade volunteers filled out perceived stress, mindfulness attention awareness, thriving and general self-efficacy scales. A total of 48 students who received higher than average scores in PSS $(\overline{\mathrm{X}}=43.91)(\mathrm{Sd}=5.29)$, and lower scores than average in MAAS ( $\bar{X}=54.87, \mathrm{Sd}=11.02$.), TS $(\overline{\mathrm{X}}=34.02$, $\mathrm{Sd}=5.97$. $)$ and GSES $(\overline{\mathrm{X}}=28.84, \mathrm{Sd}=5.42)$ were selected. 17 of 48 students volunteered to participate in the study. Later, these seventeen female students were randomly assigned to the experimental and control groups. The mean age of the experimental group was $16.62(\mathrm{Sd}=.51)$, while the control group had a mean of $16.77(\mathrm{Sd}=.41)$.

\subsection{Data collection instruments}

\subsubsection{Perceived stress scale (PSS)}

Perceived stress scale (PSS): Developed by Cohen, Kamarck, and Mermelstein (1983), this scale was later adapted into Turkish by Eskin, Harlak, Demirkiran and Dereboy (2013), and it aims to assess an individual's perceived stress level. The scale is composed of 14 items on a 5-Likert type scale and includes two subdimensions - namely perceived insufficient self-efficacy and perceived stress/distress. The item factor loads for perceived insufficient self-efficacy dimension ranged from .44 to .76 whereas it was between .18 and .74 for perceived stress/distress dimension. The internal consistency coefficient and test-retest reliability were quite high (.84 and .87 , respectively). In this study, the internal consistency coefficient for the entire scale came to .84 .

\subsubsection{Mindfulness attention awareness scale}

Mindfulness attention awareness scale (MAAS; Brown, West, Loverich, \& Biegel, 2011): This is a 14-item self-report questionnaire that uses a 6-Likert type scale and measures the respondent's receptive state of attention, observation, and awareness to the present and immediate experiences of adolescents between the ages of 14 and 18. The Turkish version was adapted by and Aydın-Sünbül and Yerin Güneri (2019). The internal consistency indicators of Cronbach alpha and test-retest reliability were 0.82 and 0.79 , respectively (Brown et al., 2011). The Cronbach alpha of the Turkish version of the scale came to 0.81 . The results of a confirmatory factor analysis supported the single factor structure of MAAS-A $(\chi 2=162.5, \quad \mathrm{df}=75, \quad \chi 2 / \mathrm{df}=2.17 ; \quad \mathrm{GFI}=0.94$, $\mathrm{CFI}=0.92 ; \mathrm{TLI}=.90 ; \mathrm{RMSEA}=0.06$ ). In this study, the Cronbach's alpha coefficient for the entire scale was valued at 81.4. 


\section{Acta Educationis Generalis \\ Volume 12, 2022, Issue 1}

\subsubsection{Thriving scale}

Thriving scale (TS; Porath, Spreitzer, Gibson, \& Garnett, 2012): The thriving scale, composed of 10 items on a 6-point Likert-type scale, was adapted into Turkish by Arici-Ozcan, Sahin, and Cankir (2020) to measure the respondent's level of thriving. It has two factors referring to vitality and learning. The scale's overall internal consistency was 0.92 for a young adult sample and 0.88 for a young professional sample (Porath et al., 2012). The model of thriving based on two-dimensions, namely learning and vitality, fit the data well at T1 $(\chi 2=214,928 \mathrm{df}=133, \mathrm{CFI}=0.981, \mathrm{IFI}=982, \mathrm{RMSEA}=0.077, \mathrm{SRMR}=0.046)$. The Cronbach's alpha coefficient for this scale was .70 and the test-retest reliability coefficient for a 6-week interval has reached to .77. The Cronbach alpha's coefficient for this study came to .76 .

\subsubsection{General self-efficacy scale}

General self-efficacy scale (GSES; Schwarzer \& Jerusalem, 1995): Revised in 1995 as a self-report scale, the GSES consists of 10 items based on a 4-point Likert-type scale. It is used to measure general self-efficacy and has been translated into 25 languages. The Cronbach's alpha coefficient for the entire scale was .86. (Scholz, Doña, Sud, \& Schwarzer, 2002). The Turkish version of the scale was adapted and validated by Aypay (2010) and revealed a two-factor structure, namely "effort and resistance" in addition to "ability and confidence." As a result of the factor analysis of Turkish version, two factors, which explain $47 \%$ of the total variance and whose eigenvalue is greater than 1 , were obtained. The factor load values of the items in the first factor are between .45 and .72 . The factor load values of the items in the second factor are between .56 and .79 . The internal consistency of the scale in total was .83, with alpha for the two factors ranging from .79 to .63 , respectively. The test-retest reliability scales were .80 . For the current study, the Cronbach's alpha coefficient for the entire scale came to .84 .

\subsection{The scope of MTP in high school students}

The program, developed by the researcher, was organized as a psychological intervention group program to increase mindfulness, thriving and self-efficacy levels and decrease perceived stress of high school students. Firstly, the researcher examined the literature in terms of the theoretical definitions of perceived stress, mindfulness, thriving and self-efficacy, in addition to the intervention programs based on these four concepts (Blecharz et al., 2014; Deane et al., 2017; Hirschi, 2009; Malow \& Austin, 2016; Scales et al., 2011; Sibinga et al., 2011; Siegel, 2007; Tacón et al., 2003). Previous research reveals that these four concepts are based on self-regulation (Deci \& Ryan, 2008; Feldman, Hayes, Kumar, Greeson, \& Laurenceau, 2006; Greason \& Cashwell, 2009; Shapiro, Carlson, Astin, \& Freedman, 2006; Spreitzer et al., 2005; Wallace et al., 2016). Accordingly, the researcher developed the mindfulness- 


\section{Acta Educationis Generalis \\ Volume 12, 2022, Issue 1}

based thriving program as in line with the self-regulation theory (Shapiro \& Schwartz, 2000). Self-regulation is the ability to consciously monitor and control the individual's own thoughts, behaviours, emotions, and bodily sensations, and can be developed through attention exercises (Shapiro \& Schwartz, 2000). Thus, the mindfulness-based thriving program involves awareness of bodily sensations, emotions, thoughts, behaviours, and their regulation, sequentially.

\subsection{The content of MTP}

MTPs for high school students refer to a six-week psychological intervention group program composed of 90-minute sessions once a week. Each session involves three activities, each activity lasting approximately 20 minutes. All sessions include a warming up, mindfulness-based thriving, and a closure activity. One of the sample activities for warming up is "Settling and Seeing". In this activity, the participants notice and sense the ground they sit and realize what their eyes attract attention in their environment. An example of the mindfulness based thriving activities is called "Changing Balls". The participants think about a stressful event they experienced during the previous week before picking a ball representing this stress among the coloured shrinking balls. They then observe their senses and feelings while holding the ball in their hand. The same procedure is applied to dwell on positive events, as well. Later, the activity ends with group members' sharing their experience. A third sample of the activities regarding the closure in a positive way is named as "Settling Experience". Participants are asked to close their eyes and feel the ground they sit to realize their past experiences of here and now. Consequently, they can place these sensations in their bodies. Table 2 summarizes the topics in each of the sessions.

Table 2

\begin{tabular}{|c|c|}
\hline \multicolumn{2}{|l|}{ Session } \\
\hline $1^{\text {st }}$ & $\begin{array}{l}\text { - } \quad \text { Meeting, group cohesion } \\
\text { - } \quad \text { Noticing the place with being conscious } \\
\text { - } \quad \text { Determining group rules and group purpose }\end{array}$ \\
\hline $2^{\text {nd }}$ & $\begin{array}{l}\text { - Noticing the body with consciousness and discovering bodily resources } \\
\text { - Talking about daily problems to-do with consciousness } \\
\text { - Becoming aware of body sensations when talking about the daily } \\
\text { - } \quad \text { Using bodily resources when speaking about daily problems }\end{array}$ \\
\hline $3^{\text {rd }}$ & $\begin{array}{l}\text { - Noticing the feelings with conscious and discovering feeling resources } \\
\text { - Becoming aware of their feelings when speaking about problems } \\
\text { - Monitoring and handling with these emotions when speaking about a } \\
\text { - } \quad \text { Utilizing feeling resources when talking about a problem }\end{array}$ \\
\hline
\end{tabular}




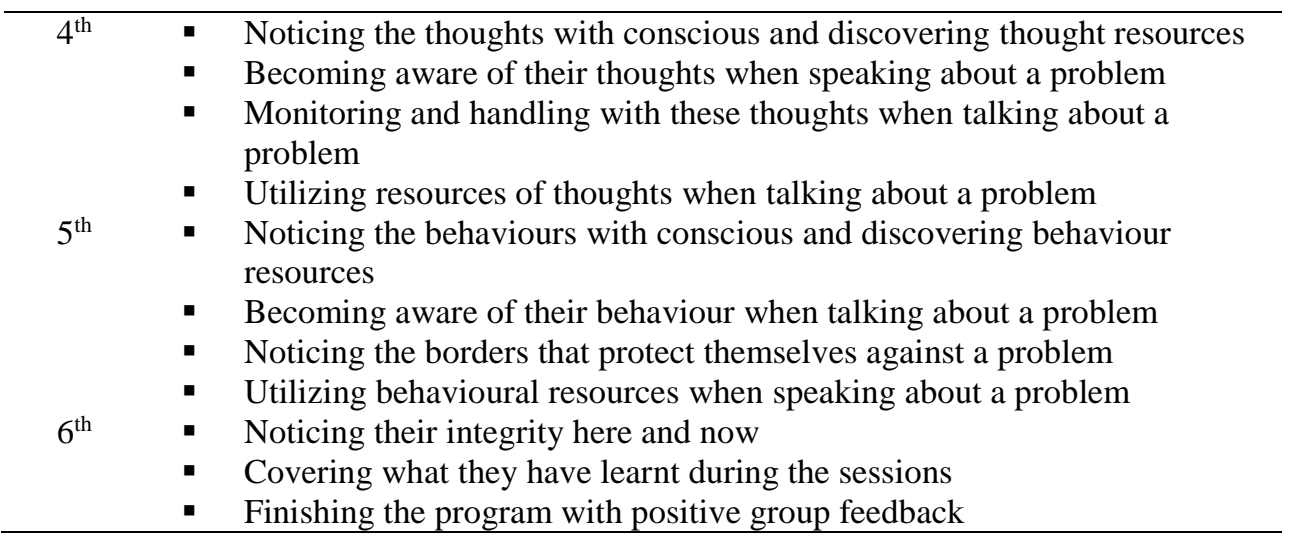

\subsection{Data analysis}

After ethical permission was approved from the Ethical Committee in Istanbul Medeniyet University. A preliminary analysis was conducted using the pre-test scores of the PSS, MAAS, TS and GSESs collected from the participants of the experimental and control groups to determine the test type (parametric or nonparametric) for the main analysis of the data. According to the results of a preliminary analysis, the data was homogeneous and distributed typically. A two-way ANOVA for repeated measurements with a $2 \times 3$ design was used to display the statistical significance of the change in pre-test, post-test and followup tests, as this is a more appropriate method for split-plot (mixed) designs (Buyukozturk, 2006). Later, the data was examined using the Tukey (HSD) test to identify the mean scores that are significantly different from each other. All statistical analyses were completed using IBM SPSS Statistics 23 and computed at $\mathrm{p} \leq .05$ and $\mathrm{p} \leq .01$.

\section{Results}

\subsection{Results on preliminary analysis}

The data set was checked for the homogeneity and normality before statistical analyses. According to the parametric test results of the pre-test measurements, there were no significant differences among the mean scores of PSS (F(1$15)=.2 .276, \mathrm{p}>.05)$, MAAS $(\mathrm{F}(1-15)=1.605, \mathrm{p}>.05)$, TS $(\mathrm{F}(1-15)=.674 \mathrm{p}>.05)$ and GSES $(\mathrm{F}(1-15)=.358 \mathrm{p}>.05)$. Furthermore, the Kolmogorov-Smirnov test of the PSS (.212, p>.05), MAAS (.180, p>.05), TS (.167, p>.05) and GSES (.131 $\mathrm{p}>.05$ ) came to a measure larger than (p) .05 (Buyukozturk, 2006). Additionally, the skewness and kurtosis level gathered from the scores of both the experimental and control groups in pre-test measurements on each of the three scales came to between +1 and -1 , which indicates a normal distribution. 


\section{Acta Educationis Generalis \\ Volume 12, 2022, Issue 1}

\subsection{Descriptive statistics for the experimental and control groups}

The arithmetic mean scores and standard deviations for all scales as a function of groups and measurements are presented in Table 3.

Table 3

Arithmetic average and standard deviation values of experimental and control groups

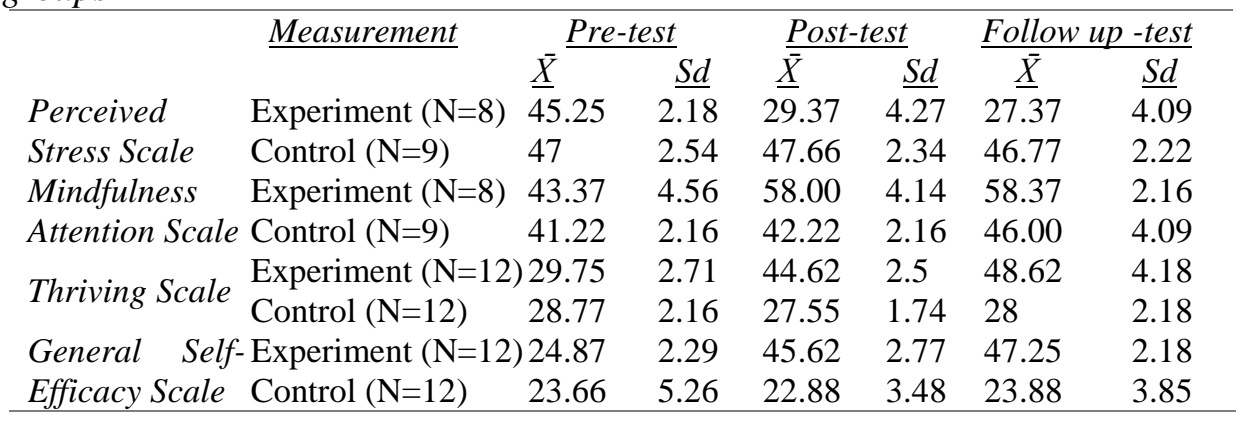

In light of Table 3, the pre-test averages for the experimental and control groups were observed as equivalent, while there showed differences between the posttests and follow up tests of either group in all the scales. Given the differences revealed in the descriptive statistics, all hypotheses were tested using a two-step procedure. First, a series of two-way repeated measures, ANOVA, were conducted on the PSS, MAAS, TS, and GSES scores to determine the differences between the experiment and control groups at the end of the intervention process. Following the ANOVA results, Tukey's test was performed for each of the scales to make comparisons among the mean scores for significant $F$ values.

\subsection{Results on hypothesis on decreasing perceived stress}

PSS scores were analysed with a 2 (Group: Experiment vs. Control) x 3 (Measurement: Pre-test, Post-test, Follow up test) repeated measures ANOVA, as shown in Table 4.

Table 4

Variance analysis results of two factors on experimental and control groups' PSS scores

\begin{tabular}{|c|c|c|c|c|c|c|}
\hline Source & $\frac{\text { Sum of }}{\text { Squares }}$ & & $\frac{\text { Average of }}{\text { Squares }}$ & $\underline{F}$ & $\underline{p}$ & $\stackrel{\text { Eta }}{\text { Square }}$ \\
\hline Between groups & $8 \overline{8668.514}$ & 14 & & & & \\
\hline Group (E/C) & 2196.514 & 1 & 219.514 & 106.487 & .000 & .877 \\
\hline Error & 309.407 & 15 & 20.627 & & & \\
\hline
\end{tabular}




\begin{tabular}{lrrrrrrr}
\hline Within groups & & 1876.052 & 17 & & & & \\
Measurement & (pre-post- & 800.680 & 1 & 400.340 & 48.546 & .000 & .764 \\
follow up) & 827.974 & 1 & 413.987 & 50.201 & .000 & .770 \\
Group*Measurement & 247.398 & 15 & 8.247 & & & \\
$\quad$ Error & &
\end{tabular}

The group effect for the PSS scale was found to be significant $(F(1-$ $15)=106.487, p<.01)$. Irrespective of the test types, there were significant differences between the average PSS scores of the experimental and control groups. Similarly, there were significant differences $(F(2-15)=31.194, p<.01)$ between the average PSS scores of individuals gathered from pre-test, post-test, and follow up tests, regardless of the group type. Furthermore, there was a significant interaction between group and measurement, such that $(\mathrm{F}(2-$ $15)=34.03, p<.01)$ the change in the scores of individuals on the PSS scale over the pre-test, post-test and follow up measurements varied depending on the group type.

Following the significant ANOVA results, a Tukey test was performed to display the significant pairwise comparisons. Post-hoc comparisons using the Tukey HSD test revealed that, as hypothesized, the pre-test mean scores of the individuals in the experimental group were 15.88 points higher than their posttest average scores $(\mathrm{p}<.01)$ and 17.88 points higher than their average follow up test scores $(\mathrm{p}<.05)$. Furthermore, post-hoc comparisons using the Tukey HSD test showed that the post-test mean scores of the individuals in the experimental group were -18.29 points lower than their post-test average scores in the control group $(\mathrm{p}<.01)$ and the follow up test mean scores of the individuals in the experimental group were -19.4 points lower than the follow-up test average scores of the control group $(\mathrm{p}<.05)$. However, the mean differences between the pre-test and post-test, follow up test scores for the control group were not significant ( $p>.05)$. Thus, it can be stated that the MTP caused a significant decrease in perceived stress levels for the experimental group.

\subsection{Results on hypothesis on increasing mindfulness}

MAAS scores were analysed with a 2 (Group: Experiment vs. Control) x 3 (Measurement: Pre-test, Post-test, Follow up test) repeated measures ANOVA, as displayed in Table 5. 


\section{Acta Educationis Generalis \\ Volume 12, 2022, Issue 1}

\section{Table 5}

Variance analysis results of two factors on experimental and control groups' MAAS scores

\begin{tabular}{lrrrrrr}
\hline$\underline{\text { Source }}$ & \multicolumn{1}{c}{$\begin{array}{c}\text { Sum } \\
\text { Squares }\end{array}$} & $\underline{\text { Sd }}$ & $\begin{array}{c}\text { Average } \\
\text { of Squares }\end{array}$ & $\underline{F}$ & $\underline{P}$ & $\begin{array}{c}\text { Eta } \\
\text { Square }\end{array}$ \\
Between groups & 117662,798 & 14 & & & & \\
$\quad$ Group (E/C) & 1428.132 & 1 & 1428.13 & 37.24 & .000 & .713 \\
$\quad 575.241$ & 15 & 38.34 & & & \\
$\quad$ Error & 1645.791 & 17 & & & & \\
Within groups & 905.752 & 1 & 452.876 & 57.66 & .000 & .794 \\
$\begin{array}{l}\text { Measurement } \\
\text { (pre-post- follow up) }\end{array}$ & & & & & & \\
$\begin{array}{l}\text { Group*Measurement } \\
\quad \text { Error }\end{array}$ & 504.419 & 1 & 252.209 & 32.11 & .000 & .682 \\
\hline
\end{tabular}

The main effect of the group on the MAAS scores were significant $(\mathrm{F}(1-$ $15)=37.24, p<.01$ ). Without discriminating between pre-test, post-test and follow up test scores, a significant difference between the MAAS average scores of the experiment and control groups can be observed. Similarly, the main effect of the measurement was also significant $(F(2-15)=57.66, p<.01)$. Regardless of the group type, the MAAS scores of each individual changed over the course of the measurement process. Furthermore, the interaction effect (group*measurement) appeared to be significant $(\mathrm{F}(2-15)=32.11, \mathrm{p}<.01)$, which showed that the change in the MAAS scores over the measurement process (pre-test, post-test, follow up test) varied according to group type (experimental or control).

Following the significant interaction effect, a Tukey test was performed to identify the significant pairwise comparisons. The Tukey post-hoc comparisons indicated that while scores for the control group did not display a significant change during the pre-test, post-test and follow up test ( $p>.05)$, there was a significant increase in the average scores of the MAAS over the experimental process for the experimental group. The pre-test mean scores of the individuals in the experimental group were 14.63 points lower than their post-test average scores $(\mathrm{p}<.01)$ and 15 points lower than their average follow up test scores $(\mathrm{p}<.01)$. Furthermore, post-hoc comparisons using the Tukey HSD test showed that the post-test mean scores of the individuals in the experimental group were 15.78 points higher than their post-test average scores in the control group $(\mathrm{p}<.01)$ and the follow up test mean scores of the individuals in the experimental group were 12.37 points higher than their follow-up test average scores in the control group $(\mathrm{p}<.01)$. As in line with the second hypothesis, the MP was significantly efficient in increasing the mindfulness levels of the experimental group. 


\subsection{Results on hypotheses on increasing thriving level}

The TS scores were analysed with a 2 (Group: Experiment vs. Control) x 3 (Measurement: Pre-test, Post-test, follow up test) repeated measures ANOVA, as presented in Table 6.

Table 6

Variance analysis results of two factors on experimental and control groups' TS scores

\begin{tabular}{|c|c|c|c|c|c|c|}
\hline Source & $\frac{\text { Sum }}{\text { of Squares }}$ & $\underline{S d}$ & $\frac{\text { Average }}{\text { of Squares }}$ & $\underline{F}$ & $\underline{P}$ & Eta \\
\hline Between groups & 60687.686 & 14 & & & & \\
\hline Group (E//C) & 2110.745 & 1 & 2110.745 & 184.07 & .000 & .925 \\
\hline Error & 172.000 & 15 & 11.46 & & & \\
\hline Within groups & 1875.364 & 17 & & & & \\
\hline $\begin{array}{l}\text { Measurement (pre-post- } \\
\text { follow up) }\end{array}$ & 753.403 & 1 & 366.702 & 58.54 & .000 & .796 \\
\hline Group*Measurement & 928.933 & 1 & 464.467 & 72.186 & .000 & .828 \\
\hline Error & 193.028 & 15 & 6.34 & & & \\
\hline
\end{tabular}

The results revealed that the group effect on TS scores was significant $(\mathrm{F}(1-$ $15)=184.07 ; p<.01)$. Irrespective of measurement type, significant differences emerged between the experimental and control groups' average scores on the TS. Likewise, the effect of the measurement was also significant $(F(2-$ $15)=58.54, \mathrm{p}<.01$ ), indicating a difference between pre-test, post-test and follow up test for the TS scores. Furthermore, it was seen that value gathered from the examination of common effect (group*measurement) was significant $(\mathrm{F}(2-$ $15)=72.186, p<.01)$. In other words, the difference between the average scores of the experimental and control groups changed depending on the measurement process.

Following the significant ANOVA results, a Tukey test was performed to display the significant pairwise comparisons. Tukey post hoc comparisons indicated that the pre-test mean scores of the individuals in the experimental group were 14.87 points lower than their post-test average scores $(\mathrm{p}<.01)$, as well as 18.87 points lower than their average follow up test scores $(\mathrm{p}<.01)$, verifying the third hypothesis of the study. Furthermore, post-hoc comparisons using the Tukey HSD test showed that the post-test mean scores of the individuals in the experimental group were 17.07 points higher than their posttest average scores in the control group $(\mathrm{p}<.01)$ and the follow up test mean scores of the individuals in the experimental group ended 20.62 points higher than their follow up test average scores in the control group ( $\mathrm{p}<.01)$. However, the mean differences among the pre-test, post-test and follow up test scores for the control group were not significant ( $p>.05)$. In other words, MTP was 
significantly efficient in increasing the mindfulness levels of the experimental group.

\subsection{Results on hypotheses on increasing self-efficacy level}

GSES scores were analysed with a 2 (Group: Experiment vs. Control) x 3 (Measurement: Pre-test, Post-test, Follow up test) repeated measures ANOVA, as shown in Table 7.

\section{Table 7}

Variance analysis results of two factors on experimental and control groups' GSES scores

\begin{tabular}{lrrrrrr}
\hline Source & $\begin{array}{r}\text { Sum of } \\
\text { Squares }\end{array}$ & \multicolumn{1}{c}{$S d$} & $\begin{array}{c}\text { Average } \\
\text { of Squares }\end{array}$ & $F$ & $p$ & $\begin{array}{c}\text { Eta } \\
\text { Square }\end{array}$ \\
\hline Between groups & 50000.681 & 14 & & & & \\
$\quad$ Group (E//C) & 3159.269 & 1 & 3159.269 & 191.284 & .000 & .873 \\
$\quad$ Error & 460.574 & 15 & 17.476 & & & \\
Within groups & 3058.667 & 17 & & & & \\
$\begin{array}{l}\text { Measurement (pre-post- } \\
\text { follow up) }\end{array}$ & 1293.762 & 1 & 681.024 & 191.284 & .000 & .927 \\
Group*Measurement & 1347.644 & 1 & 673.822 & 199.250 & .000 & .7930 \\
$\quad$ Error & 101.454 & 15 & 3.382 & & & \\
\hline
\end{tabular}

Based on the ANOVA results, the group effect was found to be significant ( $\mathrm{F}(1-$ $15)=191.284, \quad \mathrm{p}<.01)$. Regardless of pre-test, post-test and follow-up measurements, significant differences emerged between the average scores of experimental and control groups on the GSES. Similarly, there was a main significant effect of the measurement type on the average scores of individuals $(\mathrm{F}(2-15)=191.284 ; \mathrm{p}<.01)$. These main effects were qualified by a significant interaction between group and measurement $(F(2-15)=199.25 ; \mathrm{p}<.01)$. This outcome indicated that the effect of group type of average GSES scores differed depending on the pre-test, post-test and follow-up measurements.

Given the significant interaction in the ANOVA results, a Tukey test was conducted to identify which groups were significantly different from others. The Tukey post-hoc comparisons indicated that the pre-test mean scores of individuals in the experimental group were 20.75 points lower than their posttest average scores $(\mathrm{p}<.01)$ and 22.38 points lower than their average follow-up test scores $(\mathrm{p}<.01)$. Furthermore, post-hoc comparisons using the Tukey HSD test showed that the post-test mean scores of individuals in the experimental group were 22.74 points higher than their post-test average scores in the control group $(\mathrm{p}<.01)$, while the follow-up test mean scores of individuals in the experimental group were 23.37 points higher than their follow-up test averages in the control group $(\mathrm{p}<.01)$. However, the mean differences between the pretest, post-test and follow up test scores for the control group were not significant 


\section{Acta Educationis Generalis \\ Volume 12, 2022, Issue 1}

(p>.05). Verifying the fourth hypothesis, the MTP was effective in increasing the self-efficacy levels of the experimental group compared to the control group.

\section{Discussion and conclusion}

The main objective of the current study was to understand the effects of the MTP on adolescents with a higher level of perceived stress. The results of this study suggested that the 6-week MTP applied to adolescents was significantly effective in decreasing perceived stress and increasing mindfulness, thriving and self-efficacy levels.

According to the first result of this study, the implementation of a 6-week MTP was significantly effective in decreasing perceived stress levels among adolescents. This result was supportive of the earlier research showing that MBSR reduces stress and anxiety in adolescents (Bergen-Cico, Possemato, \& Cheon, 2013; Malow \& Austin, 2016; Demir, 2015; 2017; Kuyken, Weare, Ukoumunne et al., 2013). Barkan and his colleagues (2016) stated that mindfulness was also related to individual characteristics, such as openness and agreeableness, as well as awareness. In that regard, thriving also appears a related concept. Several studies (Arnold, 2017; 2018; Arnold \& Gagnon, 2019; DuBois \& Keller, 2017; Gerson \& Fernandez, 2013) indicated the role of thriving-based programs in reducing stress among adolescents. Hence, it is possible to develop more comprehensive and effective programs by combining the elements of mindfulness and thriving in one study.

The second finding indicated that MTP was significantly effective in increasing the mindfulness levels of adolescents, which was compatible with the results of previous studies (Ames, Richardson, Payne, Smith, \& Leigh, 2014; Atalay et al., 2017; Huppert \& Johnson, 2010). This study is the first to integrate thriving into a mindfulness program and was effective in increasing the mindfulness level of adolescents.

The third finding further suggested that MTP was significantly effective in increasing the thriving level of adolescents. As expected, thriving programs (Arnold, 2017, 2018; Arnold \& Gagnon, 2019; DuBois \& Keller, 2017; Lerner et al., 2009, Lerner et al., 2011) are effective in increasing the adolescences' thriving level. Although previous research examined the relationship between mindfulness and thriving (Allen \& Kiburz, 2012; Baer \& Lykins, 2011; Şahin et al., 2020; Tan \& Martin, 2015; Warren, 2016) for various samples (workers, nurses, adolescence), no experimental studies were shown to be effective in increasing the thriving level of adolescents.

Similarly, our last finding showed that MTP was significantly effective in increasing the self-efficacy level of adolescents. This finding was in line with the studies indicating the role of mindfulness (Atalay et al., 2017; Blecharz et al., 2014; Ozkan et al., 2018; Pepping, Duvenage, Cronin, \& Lyons, 2016) and thriving programs (Arnold, 2017, 2018; Arnold \& Gagnon, 2019; DuBois \& 


\section{Acta Educationis Generalis}

Volume 12, 2022, Issue 1

Keller, 2017; Gerson \& Fernandez, 2013) in reducing stress as well as improving self-efficacy in adolescence.

Considering all these mentioned statements, this study has a number of important contributions. First, MTP bridges an important gap in literature, especially regarding self-efficacy. As Cicognani (2011) states, adolescents' perception of self-efficacy plays a critical role in the construction of their personality and strategies to cope with the challenges they face. This study makes a crucial contribution by explaining that both thriving and mindfulness has an important role in the development of self-efficacy during adolescence. Most such thriving and mindfulness practices that exist in the literature have their basis in adult-based practices. Since adolescents have less developed memories and attention skills compared to older subjects, modifications are required accordingly (Posner \& Petersen, 1990). The program applied in this study differs from that featured in the literature, in this respect, and its content is arranged in accordance with the developmental process of the adolescence. The unique features that distinguish this program from other applications mainly concern its mindfulness and thriving basis, eclectic theoretical framework and a multi-structural nature that presents elements aimed at supporting adolescent development through a biopsychosocial model. The program is structured and is open for the benefit of specialists working in the field, including those based in schools, training centres, and guidance centres. Thanks to its holistic perspective and adolescent focus, the program provides a unique contribution to the literature.

Despite the contribution of this research, there were some limitations. The first concerns the scores obtained from the scales. Data were collected via self-report questionnaires so that social desirability may have effect on the research. Secondly, the sample is composed of only 11th grade female students, which limits the generalizability of the results. Therefore, this research can be tested on more diverse and heterogeneous gender adolescent groups. Third, the current study only contained experimental and control groups. Henceforth, adding a placebo group would increase the reliability of the results. Fourth, a single program was applied to the participants with no comparison having been made to a different program. Thus, a practical comparison with other programs in the literature would enhance the validity of these findings. Finally, the results obtained at the end of the 6-week program were compared with the results of two months after the program and the effect was evaluated. Lack of a follow up of this effect at certain intervals can thus also be counted among the study's limitations. 


\section{Acta Educationis Generalis \\ Volume 12, 2022, Issue 1}

\section{References}

Ames, C. S., Richardson, J., Payne, S., Smith, P., \& Leigh, E. (2014). Mindfulness-based cognitive therapy for depression in adolescents. Child and Adolescent Mental Health, 19(1), 74-78. https://doi.org/10.1111/camh.12034

Allen, T. D., \& Kiburz, K. M. (2012). Trait mindfulness and work-family balance among working parents: The mediating effects of vitality and sleep quality. Journal of Vocational Behavior, 80(2), 372-379. https://doi.org/10.1016/j.jvb.2011.09.002

Arici-Ozcan, N., Sahin, S., \& Cankir, B. (2020). The validity and reliability of thriving scale in academic context: mindfulness, GPA, and entrepreneurship among university students (Unpublished Manuscript).

Arnett, J. J. (2007). Emerging adulthood: What is it, and what is it good for?. Child Development Perspectives, 1(2), 68-73. https://doi.org/10.1111/j.1750-8606.2007.00016.x

Arnold, E. (2017). Supporting adolescent exploration and commitment: Identity formation, thriving, and positive youth development. Journal of Youth Development, 12(4), 1-15. https://doi.org/10.5195/jyd.2017.522

Arnold, M. E. (2018). From context to outcomes: A thriving model for 4-H youth development programs. Journal of Human Sciences and Extension, 6(1), 141-160.

Arnold, M. E., \& Gagnon, R. J. (2019). Illuminating the process of youth development: The mediating effect of thriving on youth development program outcomes. Journal of Human Sciences and Extension, 7(3), 24-51.

Astin, J. A. (1997). Stress reduction through mindfulness meditation. Psychotherapy and Psychosomatics, 66(2), 97-106. https://doi.org/10.1159/000289116

Atalay, Z., Bulgan, G, \& Taylan, R. D. (2017). Mindfulness-Based Self Efficacy Scale-Revised (MSES-R): Turkish adaptation study. Elementary Education Online, 16(4), 1803-1815.

Aydın Sünbül, Z., \& Yerin Güneri Y. (2019). The relationship between mindfulness and resilience: The mediating role of self-compassion and emotion regulation in a sample of underprivileged Turkish adolescents. Personality and Individual Differences, 139, 337-342. https://doi.org/10.1016/j.paid.2018.12.009

Aypay, A. (2010). The adaptation study of General Self Efficacy (GSE) Scale to Turkish. Inonu University Journal of the Faculty of Education, 11(2), 113-131.

Baer, R. A., \& Lykins, E. L. M. (2011). Mindfulness and positive psychological functioning. Designing Positive Psychology: Taking Stock and Moving Forward, 335-348. https://doi.org/10.1093/acprof:oso/9780195373585.003.0022

Barkan, T., Hoerger, M., Gallegos, A. M., Turiano, N. A., Duberstein, P. R., \& Moynihan, J. A. (2016). Personality predicts utilization of mindfulness-based stress reduction during and post-intervention in a community sample of older adults. The Journal of Alternative and Complementary Medicine, 22, 390-95. https://doi.org/10.1089/acm.2015.0177

Beauchemin, J., Hutchins, T. L., \& Patterson, F. (2008). Mindfulness meditation may lessen anxiety, promote social skills, and improve academic performance among adolescents with learning disabilities. Complementary Health Practice Review, 13(1), 34-45. https://doi.org/10.1177/1533210107311624

Bergen-Cico, D., Possemato, K., \& Cheon, S. (2013). Examining the efficacy of a brief mindfulness-based stress reduction (brief MBSR) program on psychological health. Journal of American College Health, 61(6), 348-360. https://doi.org/10.1080/07448481.2013.813853

Bishop, S. R., Lau, M., Shapiro, S., Carlson, L., Anderson, N. D., Carmody, J., Segal, Z. V., Abbey, S., Speca, M., Velting, D., \& Devins, G. (2004). Mindfulness: A proposed operational definition. Clinical Psychology: Science and Practice, 11, 230-241. https://doi.org/10.1093/clipsy.bph077

Blecharz, J., Luszczynska, A., Scholz, U., Schwarzer, R., Siekanska, M., \& Cieslak, R. (2014). Predicting performance and performance satisfaction: Mindfulness and beliefs about the ability to deal with social barriers in sport. Anxiety, Stress, and Coping, 27(3), 270-287. https://doi.org/10.1080/10615806.2013.839989 


\section{Acta Educationis Generalis \\ Volume 12, 2022, Issue 1}

Brown, K. W., \& Ryan, R. M. (2003). The benefits of being present: Mindfulness and its role in psychological well-being. Journal of Personality and Social Psychology, 84(4), 822-848. https://doi.org/10.1037/0022-3514.84.4.822

Brown, K. W., West, A. M., Loverich, T. M., \& Biegel, G. M. (2011). Assessing adolescent mindfulness: Validation of an Adapted Mindful Attention Awareness Scale in adolescent normative and psychiatric populations. Psychological Assessment, 23(4), 1023. https://doi.org/10.1037/a0021338

Brown, D. J., Arnold, R., Fletcher, D., \& Standage, M. (2017). Human thriving. European Psychologist, 22(3), 167-179. https://doi.org/10.1027/1016-9040/a000294

Bundick, M. J., Yeager, D. S., King, P. E., \& Damon, W. (2010). Thriving across the life span. The handbook of life-span development. https://doi.org/10.1002/9780470880166.hlsd001024

Buyukozturk, S. (2006). Experimental designs pretest-posttest control group design and data analysis. Ankara: Pegem Publishing.

Byrne, D. G., Davenport, S. C., \& Mazanov, J. (2007). Profiles of adolescent stress: The development of the adolescent stress questionnaire (ASQ). Journal of Adolescence, 30(3), 393-416. https://doi.org/10.1016/j.adolescence.2006.04.004

Caldwell, K., Harrison, M., Adams, M., Quin, R. H., \& Greeson, J. (2010). Developing mindfulness in college students through movement-based courses: Effects on self-regulatory self-efficacy, mood, stress, and sleep quality. Journal of American College Health, 58(5), 433-442. https://doi.org/10.1080/07448480903540481

Cayoun, B. A., Francis, S. E., Kasselis, N., \& Skilbeck, C. (2012). Mindfulness-Based Self Efficacy Scale-Revised (MSES-R).

Chang, V. Y., Palesh, O., Caldwell, R., Glasgow, N., Abramson, M., Luskin, F., Gill, M., Burke, A., \& Koopman, C. (2004). The effects of a mindfulness-based stress reduction program on stress, mindfulness self-efficacy, and positive states of mind. Stress and Health: Journal of the International Society for the Investigation of Stress, 20(3), 141-147. https://doi.org/10.1002/smi.1011

Cicognani, E. (2011). Coping strategies with minor stressors in adolescence: Relationships with social support, self-efficacy, and psychological well-being. Journal of Applied Social Psychology, 41(3), 559-578. https://doi.org/10.1111/j.1559-1816.2011.00726.x

Coffman, D. D. (2007). An exploration of personality traits in older adult amateur musicians. Research and Issues in Music Education, 5(1), 1-12.

Cohen, S., Kamarck, T., \& Mermelstein, R. (1983). A global measure of perceived stress. Journal of Health and Social Behavior, 385-396. https://doi.org/10.2307/2136404

Cohen-Katz, J., Wiley, S. D., Capuano, T., Baker, D. M., \& Shapiro, S. (2005). The effects of mindfulness-based stress reduction on nurse stress and burnout, Part II: A quantitative and qualitative study. Holistic Nursing Practice, 19(1), 26-35. https://doi.org/10.1097/00004650200501000-00008

Creswell, J. D., Way, B. M., Eisenberger, N. I., \& Lieberman, M. D. (2007). Neural correlates of dispositional mindfulness during affect labeling. Psychosomatic Medicine, 69(6), 560-565. https://doi.org/10.1097/psy.0b013e3180f6171f

Davidson, R. J., Kabat-Zinn, J., Schumacher, J., Rosenkranz, M., Muller, D., Santorelli, S. F., Urbanowski, F., Harrington, A., Bonus, K., \& Sheridan, J. F. (2003). Alterations in brain and immune function produced by mindfulness meditation. Psychosomatic Medicine, 65(4), 564570. https://doi.org/10.1097/01.psy.0000077505.67574.e3

Deane, K. L., Harré, N., Moore, J., \& Courtney, M. G. (2017). The impact of the Project K youth development program on self-efficacy: A randomized controlled trial. Journal of Youth and Adolescence, 46(3), 516-537. https://doi.org/10.1007/s10964-016-0463-9

Deci, E. L., \& Ryan, R. M. (2008). Facilitating optimal motivation and psychological well-being across life's domains. Canadian Psychology/Psychologie Canadienne, 49(1), 14. https://doi.org/10.1037/0708-5591.49.3.262 


\section{Acta Educationis Generalis \\ Volume 12, 2022, Issue 1}

Demir, V. (2015). The effects of mindfulness based cognitive therapy program on depressive symptoms of individuals. Studies in Psychology, 35(1), 15-26.

Demir, V. (2017). Effects of mindfulness based cognitive therapy on the anxiety levels of university students. International Journal of Society Researches, 7(12), 98-118.

Demir, V., \& Gündoğan, N. A. (2018). The effectiveness of mindfulness based cognitive therapy program on decreasing the emotion regulation difficulties of university students. Ege Journal of Education, 19(1), 46-66.

Dogan, H., \& Kuzgun, Y. (2008). The effect of informative consultancy program on university entry exam and wrong beliefs on university education. Selçuk University Journal of Social Sciences Institute, 20, 291-306.

DuBois, D. L., \& Keller, T. E. (2017). Investigation of the integration of supports for youth thriving into a community-based mentoring program. Child Development, 88(5), 1480-1491. https://doi.org/10.1111/cdev.12887

Eskin, M., Harlak, H., Demirkiran, F., \& Dereboy, C. (2013). The adaptation of the perceived stress scale into Turkish: A reliability and validity analysis. In Journal of New Symposium, 51, 132-140.

Feldman, G., Hayes, A., Kumar, S., Greeson, J., \& Laurenceau, J. (2006). Mindfulness and emotion regulation: The development and initial validation of the Cognitive and Affective Mindfulness Scale-Revised (CAMS-R). Journal of Psychopathology and Behavioral Assessment, 29(3), 177. https://doi.org/10.1007/s10862-006-9035-8

Franco, C., Mañas, I., Cangas, A. J., \& Gallego, J. (2010). The applications of mindfulness with students of secondary school: Results on the academic performance, self-concept, and anxiety. In World Summit on Knowledge Society (pp. 83-97). Berlin, Heidelberg: Springer. https://doi.org/10.1007/978-3-642-16318-0_10

Gerson, M. W., \& Fernandez, N. (2013). PATH: A program to build resilience and thriving in undergraduates. Journal of Applied Social Psychology, 43(11), 2169-2184. https://doi.org/10.1111/jasp.12168

Greason, P. B., \& Cashwell, C. S. (2009). Mindfulness and counseling self-efficacy: The mediating role of attention and empathy. Counselor Education and Supervision, 49(1), 2-19. https://doi.org/10.1002/j.1556-6978.2009.tb00083.x

Hevedanl, M., \& Ekici, G. (2011). Analyzing high school students' attitudes towards the student selection examination (SSE) in different variables (The case of Diyarbakir). Dicle University Journal of Ziya Gökalp Faculty of Education, 17, 64-79.

Hirschi, A. (2009). Career adaptability development in adolescence: Multiple predictors and effect on sense of power and life satisfaction. Journal of Vocational Behavior, 74, 145-155. https://doi.org/10.1016/j.jvb.2009.01.002

Hölzel, B. K., Lazar, S. W., Gard, T., Schuman-Olivier, Z., Vago, D. R., \& Ott, U. (2011). How does mindfulness meditation work? Proposing mechanisms of action from a conceptual and neural perspective. Perspectives on Psychological Science, 6(6), 537-559.

Huppert, F. A., \& Johnson, D. M. (2010). A controlled trial of mindfulness training in schools: The importance of practice for an impact on well-being. The Journal of Positive Psychology, 5(4), 264-274. https://doi.org/10.1080/17439761003794148

Kabat-Zinn, J. (2015). Mindfulness. Mindfulness, 6, 1481-1483. https://doi.org/10.1007/s12671015-0456-x

Kuyken, W., Weare, K., Ukoumunne, O. C., Vicary, R., Motton, N., Burnett, R., Cullen, C., Hennelly, S., \& Huppert, F. (2013). Effectiveness of the mindfulness in schools program: Non-randomized controlled feasibility study. The British Journal of Psychiatry, 203(2), 126131. https://doi.org/10.1192/bjp.bp.113.126649

Lerner, J. V., Phelps, E., Forman, Y., \& Bowers, E. P. (2009). Positive youth development. In R. M. Lerner, \& L. Steinberg (Eds.), Individual bases of adolescent development (pp. 524-558). Vol. 1 in Handbook of adolescent psychology (3rd ed.). Hoboken, NJ: Wiley. https://doi.org/10.1002/9780470479193.adlpsy001016 


\section{Acta Educationis Generalis \\ Volume 12, 2022, Issue 1}

Lerner, R. M., Lerner, J. V., von Eye, A., Bowers, E. P., \& Lewin-Bizan, S. (2011). Individual and contextual bases of thriving in adolescence: A view of the issues. Journal of Adolescence, 34(6), 1107-1114. https://doi.org/10.1016/j.adolescence.2011.08.001

Malow, M. S., \& Austin, V. L. (2016). Mindfulness for students classified with emotional/behavioural disorder. Insights into Learning Disabilities, 13(1), 81-93.

Melman, S., Little, S. G., \& Akin-Little, K. A. (2007). Adolescent overscheduling: The relationship between levels of participation in scheduled activities and self-reported clinical

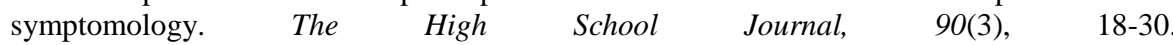
https://doi.org/10.1353/hsj.2007.0011

Muris, P., Meesters, C., Pierik, A., \& de Kock, B. (2016). Good for the self: Self-compassion and other self-related constructs in relation to symptoms of anxiety and depression in nonclinical youths. Journal of Child and Family Studies, 25(2), 607-617. https://doi.org/10.1007/s10826-015-0235-2

Neff, K. D., \& McGehee, P. (2010). Self-compassion and psychological resilience among adolescents and young adults. Self and Identity, 9(3), 225-240. https://doi.org/10.1080/15298860902979307

Nielsen, L., \& Kaszniak, A. W. (2006). Awareness of subtle emotional feelings: A comparison of long-term meditators and nonmeditators. Emotion, 6(3), 392. https://doi.org/10.1037/15283542.7.4.754

Nix, G. A., Ryan, R. M., Manly, J. B., \& Deci, E. L. (1999). Revitalization through self-regulation: The effects of autonomous and controlled motivation on happiness and vitality. Journal of Experimental Social Psychology, 35(3), 266-284. https://doi.org/10.1006/jesp.1999.1382

Ozkan, O., Karatas, H., \& Ergin, A. (2018). Examination of mindfulness-based self-efficacy levels of primary school students. Mediterranean Journal of Educational Research, 12(26), 503525.

Ozyeşil, Z. (2011). The Investigation of University students' Self-Compassion Levels with respect to mindfulness, Personality Traits and Demographic Variables (Unpublished doctoral thesis). Konya: Selçuk University, Institute of Educational Sciences.

Pepping, C. A., Duvenage, M., Cronin, T. J., \& Lyons, A. (2016). Adolescent mindfulness and psychopathology: The role of emotion regulation. Personality and Individual Differences, 99, 302-307. https://doi.org/10.1016/j.paid.2016.04.089

Porath, C., Spreitzer, G., Gibson, C., \& Garnett, F. G. (2012). Thriving at work: Toward its measurement, construct validation, and theoretical refinement. Journal of Organizational Behavior, 33(2), 250-275. https://doi.org/10.1002/job.756

Posner, M. I., \& Petersen, S. E. (1990). The attention system of the human brain. Annual Review of Neuroscience, 13(1), 25-42.

Scales, P. C., Benson, P. L., \& Roehlkepartain, E. C. (2011). Adolescent thriving: The role of sparks, relationships, and empowerment. Journal of Youth and Adolescence, 40(3), 263-277. https://doi.org/10.1007/s10964-010-9578-6

Scholz, U., Doña, B. G., Sud, S., \& Schwarzer, R. (2002). Is general self-efficacy a universal construct? Psychometric findings from 25 countries. European Journal of Psychological Assessment, 18(3), 242. https://doi.org/10.1027//1015-5759.18.3.242

Schwarzer, R., \& Jerusalem, M. (1995). Generalized Self-Efficacy scale. In J. Weinman, S. Wright, \& M. Johnston, Measures in health psychology: A user's portfolio. Causal and control beliefs (pp. 35-37). NFER-Nelson.

Shapiro, S. L., \& Schwartz, G. E. (2000). The role of intention in self-regulation: Toward intentional systemic mindfulness. In Handbook of self-regulation (pp. 253-273). Academic Press. https://doi.org/10.1016/b978-012109890-2/50037-8

Shapiro, S. L., Carlson, L. E., Astin, J. A., \& Freedman, B. (2006). Mechanisms of mindfulness. Journal of Clinical Psychology, 62(3), 373-386. 


\section{Acta Educationis Generalis \\ Volume 12, 2022, Issue 1}

Sibinga, E. M., Kerrigan, D., Stewart, M., Johnson, K., Magyari, T., \& Ellen, J. M. (2011). Mindfulness based stress reduction for urban youth. The Journal of Alternative and Complementary Medicine, 17(3), 213-218. https://doi.org/10.1089/acm.2009.0605

Siegel, D. J. (2007). The mindful brain: Reflection and attunement in the cultivation of well-being. WW Norton and Co.

Spreitzer, G. M., Sutcliffe, K., Dutton, J., Sonenshein, S., \& Grant, A. M. (2005). A socially embedded model of thriving at work. Organization Science, 16(5), 537-549. https://doi.org/10.1287/orsc. 1050.0153

Şahin, H., Gunay, T., \& Bati, H. (2006). University entrance exam anxiety of senior high school students in the Province of Izmir, District of Bornova. Journal of Continuing Medical Education, 5, 107-11.

Şahin, S., Arıcı Özcan, N., \& Arslan Babal, R. (2020). The mediating role of thriving: Mindfulness and contextual performance among Turkish nurses. Journal of Nursing Management, 28, 175-184. https://doi.org/10.1111/jonm.12911

Tacón, A. M., McComb, J., Caldera, Y., \& Randolph, P. (2003). Mindfulness meditation, anxiety reduction, and heart disease: A pilot study. Family and Community Health, 26(1), 25-33. https://doi.org/10.1097/00003727-200301000-00004

Tan, L., \& Martin, G. (2015). Taming the adolescent mind: A randomized controlled trial examining clinical efficacy of an adolescent mindfulness-based group program. Child and Adolescent Mental Health, 20, 49-55. https://doi.org/10.1111/camh.12057

Tuncer, N. (2017). The Study of Mindful Attention Awareness and Life Satisfaction Levels According to Social Anxiety Levels of a Group of University Students (Master's thesis). İstanbul: Işık University, Institute of Social Sciences.

Ülev, E. (2014). The Relationship between Mindfulness and Coping Styles with Depression, Anxiety and Stress Symptoms in University Students (Master's thesis). Ankara: Hacettepe University, Institute of Social Sciences.

Wallace, J. C., Butts, M. M., Johnson, P. D., Stevens, F. G., \& Smith, M. B. (2016). A multilevel model of employee innovation: Understanding the effects of regulatory focus, thriving, and employee involvement climate. Journal of Management, 42(4), 982-1004. https://doi.org/10.1177/0149206313506462

Warren, M. T. (2016). Becoming Who They Want to Be: Cross-National and In-Depth Examinations of Value-Behavior Concordance, Mindfulness, and Thriving in Adolescence (Unpublished thesis). The Claremont Graduate University, ProQuest Dissertations Publishing. 10143653.

Zenner, C., Herrnleben-Kurz, S., \& Walach, H. (2014). Mindfulness-based interventions in schools: A systematic review and meta-analysis. Frontiers in Psychology, 5, 603. https://doi.org/10.3389/fpsyg.2014.00603 